\title{
Kernos
}

Revue internationale et pluridisciplinaire de religion grecque antique

$25 \mid 2012$

Varia

\section{Julien ALIQUOT, Inscriptions grecques et latines de la Syrie. Tome 11 : Mont Hermon (Liban et Syrie)}

\section{Corinne Bonnet}

\section{(2) OpenEdition \\ Journals}

\section{Édition électronique}

URL : http://journals.openedition.org/kernos/2083

DOI : 10.4000/kernos.2083

ISSN : 2034-7871

\section{Éditeur}

Centre international d'étude de la religion grecque antique

\section{Édition imprimée}

Date de publication : 26 octobre 2012

Pagination : 378-379

ISSN : 0776-3824

Référence électronique

Corinne Bonnet, « Julien Alıquot, Inscriptions grecques et latines de la Syrie. Tome 11 : Mont Hermon (Liban et Syrie) », Kernos [En ligne], 25 | 2012, mis en ligne le 01 octobre 2012, consulté le 21

septembre 2020. URL : http://journals.openedition.org/kernos/2083 ; DOI : https://doi.org/10.4000/ kernos.2083

Ce document a été généré automatiquement le 21 septembre 2020.

Kernos 


\title{
Julien ALIQUOT, Inscriptions grecques et latines de la Syrie. Tome 11 : Mont Hermon (Liban et Syrie)
}

\author{
Corinne Bonnet
}

\section{RÉFÉRENCE}

Julien ALIQUOT, Inscriptions grecques et latines de la Syrie. Tome 11 : Mont Hermon (Liban et Syrie), Beyrouth, Presses de l'Institut français du Proche-Orient, 2008. 1 vol. $22 \times 28 \mathrm{~cm}$, 157 p . + résumé en arabe (Bibliothèque archéologique et historique, 183). ISBN :

978-2-35159-079-9.

1 Julien Aliquot (J.A.) s'est remarquablement acquitté de l'édition de 55 inscriptions provenant de l'Hermon, cette colossale chaîne montagneuse qui constitue un prolongement méridional de l'Antiliban et domine une région à part entière. Il faut $\mathrm{y}$ ajouter 25 textes supplémentaires publiés en Appendice. L'A. a ainsi fait fructifier un important dossier épigraphique inédit rassemblé par le père René Mouterde et resté en l'état depuis sa mort en 1961. Repris à nouveaux frais, enrichi de données nouvelles, affiné grâce à diverses missions au Liban et en Syrie, ce corpus des inscriptions grecques et latines de l'Hermon retiendra l'attention des spécialistes de la religion grecque à divers titres. Avant d'y venir, signalons que le volume s'ouvre sur une présentation géographique très soigneuse de la région dont le paysage est marqué par la montagne imposante qui culmine à 2814 mètres d'altitude. Divinisé dès l'Antiquité, le mont Hermon était en quelque sorte un gigantesque sanctuaire à ciel ouvert, dont J.A. suit les ramifications en tous lieux et à toutes les époques jusqu'à l'insertion des ruines de tombeaux ou de temples romains dans des lieux de prière druzes. Toutes sortes d'informations utiles sont apportées sur le climat, la faune, la flore, la toponymie et l'exploration de cette région à partir du début du XIX siècle. C'est ainsi que les connaissances topographiques, archéologiques et épigraphiques sur l'Hermon 
s'enrichissent progressivement, jusqu'à la moisson de 19 textes nouveaux due précisément aux prospections effectuées par l'A. L'Introduction se poursuit avec des considérations sur l'anthropisation de cette région, l'apparition de villages et sanctuaires, la structuration de l'espace en territoires qui font l'objet d'une brève présentation. D'excellentes cartes accompagnent le texte, ainsi qu'un certain nombre de plans, photographies des sites et des inscriptions (dans le corpus proprement dit).

Le corpus est présenté selon un ordre géographique distinguant des secteurs en fonction de l'appartenance aux territoires libanais ou syrien, avec une progression nord-sud à l'intérieur de chaque secteur. Chaque site est l'objet d'une présentation générale décrivant les lieux et les découvertes, dressant le contexte historique concerné. Chaque inscription est présentée, illustrée par une photo ou un dessin, accompagnée d'une bibliographie très complète, d'une transcription et d'une traduction. Un apparat critique tire au clair les difficultés de lecture tandis qu'un commentaire, riche et équilibré, expose les diverses options interprétatives et souligne l'intérêt documentaire du texte sur divers plans (politique, religieux, onomastique, etc.). J.A., auteur d'une magnifique synthèse sur La vie religieuse au Liban sous l'empire romain (Beyrouth, 2009), maîtrise parfaitement cette matière et est précisément attentif aux questions cultuelles. On signalera donc, pour les spécialistes, outre les formulaires traditionnels de dédicaces et d'épitaphes, une mention de Mélicerte, qualifié de « dieu ange » (inscription $n^{\circ} 1$ ) et plusieurs mentions de Leucothéa (20 et 22 [implicites], 21, $23,35,39)$, celle d'un dieu et d'un Zeus ancestral $(12,14)$, celle d'un Zeus megistos (38) et d'un Zeus du village d'Ornéa (42), celle d'un « dieu viril » (theos andrios), celle de la Thea Syria des Hiérapolitains vénérée par un esclave sacré qui fit d'innombrables tournéesquêtes pour la déesse (45), celle enfin d'un dieu "qui est Dana » (A/12), diverses mentions d'offices cultuels, grand-prêtre, prêtre, episkopos, épimélètes, katochos $(4,7$, $13,15,16,19,22,23,24,25,27,29,38,39,46,47, \mathrm{~A} / 1, \mathrm{~A} / 2)$, la dédicace d'un siège aux dieux de Kiboreia (4), des offrandes pour le salut des empereurs (17, 39, A/3, A/16, A/ $18, A / 21)$, des mentions de caisses sacrées, pratiquant éventuellement le prêt $(7,22,23$, $24,27,28,42,46,47,52)$, des références à un ordre divin $(34,40)$, à un oracle reçu en songe $(\mathrm{A} / 17)$ ou à un serment $(40)$, sans oublier la mention d'un personnage « enseveli

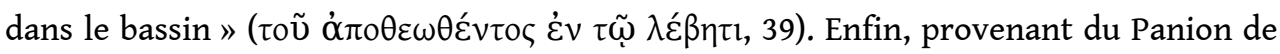
Césarée-Panéas, on dispose d'un petit corpus mentionnant Pan, Zeus, Écho, les Nymphes, Maia, Hermès, Némésis (A/13-21). L'examen de l'ensemble de cette documentation fait ressortir le puissant enracinement local des dieux vénérés, souvent soulignés par une épiclèse topique.

3 Le volume est complété par une annexe rassemblant les mentions épigraphiques de Panéas hors de la ville (p. 111-112) et par un index onomastique commenté (p. 113-124). Des indices, une concordance, une bibliographie et un résumé en arabe complètent ce volume à tous égards exemplaire. 


\section{AUTEURS}

\section{CORINNE BONNET}

Université de Toulouse - Le Mirail / IUF 